unable to detect any lactate dehydrogenase activity in a number of media that contained high activities of 'extracellularly' released enzyme, although lactate dehydrogenase activity is considerable in the synovial cells.

Rabbits that received either one or two injections of Congo Red showed similar patterns of enzyme activity for both the tissue-extract $N$-acetyl- $\beta$-Dglucosaminidase activity and the 'extracellular' enzyme. Increased activities were always found in the Congo Red-injected knees. The elevated enzyme activities in the animals that had received one injection fell to about normal by 2 weeks after the injection, but the enzyme activities were still slightly elevated in the animals that had received two injections 3 weeks previously. Changes in the elevation were even more marked in animals that had received four injections. Elevated enzyme activities were found for at least 6 weeks after the last injection. The relationship of the experimental disease process and the enzyme changes will be discussed.

Dingle, J. T. (1962). Proc. R. Soc. Med. 55, 109.

Dingle, J. T. (1966). In Modern Trends in Rheumatology, p. 110. Ed. by Hill, A. G. S. London: Butterworths.

Hayashi, M. (1965). J. Histochem. Cytochem. 13, 355.

Hendry, N. G. C. \& Carr, A. J. (1963). Nature, Lond., 199, 392.

Sellinger, O. Z., Beaufay, H., Jacques, P., Doyen, A. \& de Duve, C. (1960). Biochem. J. 74, 450.

Thomas, D. P. P. (1967). In Rheumatology, vol. 1, p. 29. Ed. by Rotstein, J. Basle: S. Karger.

\section{Localization of $\boldsymbol{N}$-Acetyl- $\boldsymbol{\beta}$-Glucosaminidase on Rat Liver Membranes}

By D. Robinson [Department of Biochemistry, Queen Elizabeth College (University of London), London W.8] and J. L. StirLing (Makerere College, Kampala, Uganda)

Two forms of $N$-acetyl- $\beta$-glucosaminidase, distinguishable by their electrophoretic mobility, have been demonstrated in a number of tissues (Robinson \& Stirling, 1968). The rapid anodic mobility of glucosaminidase A is attributed to sialic acid residues and both $A$ and $B$ forms occur in preparations of rat liver lysosomes. In the $3.5 \times 10^{5} \mathrm{~g}$ min. supernatant from differential centrifugation of homogenates in $0.25 \mathrm{M}$-sucrose, the $\mathrm{A}$ form predominates. Conchie \& Hay (1963) and Weismann, Rowin, Marshall \& Frederici (1967) have observed that the enzyme is tightly bound to particulate matter after the lysosomal particles have been ruptured, and other glycosidases, e.g. $\beta$-glucosidase (Beck \& Tappel, 1968) and $\beta$-glucuronidase (Fishman, Goldman \& DeLellis, 1967), are thought to be associated with membranes.
The existence of sialic acid in one of the forms of $N$-acetyl- $\beta$-glucosaminidase suggests that this also may arise from membrane elements.

Plasma membranes were prepared from a rat liver homogenate in $1 \mathrm{~mm}-\mathrm{NaHCO}_{3}$. This was filtered through muslin and centrifuged at $3000 \mathrm{~g}$ for $5 \mathrm{~min}$. in an MSE 18 centrifuge. The resulting pellet was resuspended in $1 \mathrm{~mm}-\mathrm{NaHCO}_{3}$ and fractionated by zonal centrifugation in the MSE 'A' rotor at $5000 \mathrm{rev} . / \mathrm{min}$. for $2 \mathrm{hr}$. at $5^{\circ}$. The sucrose density gradient used was first steep [8-40\% (w/w) in $300 \mathrm{ml}$.] followed by a slow rise in density $(40-60 \%, w / w)$ in a further $900 \mathrm{ml}$. Much of the $N$-acetyl- $\beta$-glucosaminidase remained in the steep portion of the gradient, but a small peak of activity was recovered at $d=1 \cdot 22$. This fraction had $5^{\prime}$ nucleotidase and glucose 6-phosphatase activity, but very low amounts of other lysosomal enzymes, and when the particulate matter had been recovered by centrifugation electron microscopy revealed extensive sheets of plasma membranes, some still in apposition, but no traces of mitochondria or intact lysosomes.

Similar results have been obtained with a membrane preparation from human spleen prepared by the method of Takenchi \& Terayama (1965), and a preparation of erythrocyte 'ghosts' has also been shown to have $N$-acetyl- $\beta$-glucosaminidase activity.

It is possible that the $A$ form of the enzyme may arise from an association with plasma-membrane elements whereas the B form is that initially sequestered in primary lysosomes.

Beck, C. \& Tappel, A. L. (1968). Biochim. biophys. Acta, $151,159$.

Conchie, J. \& Hay, A. J. (1963). Biochem. J. 87, 354.

Fishman, W. H., Goldman, S. S. \& DeLellis, R. (1967). Nature, Lond., 213, 457.

Robinson, D. \& Stirling, J. L. (1968). Biochem. J. 107, 321. Takenchi, M. \& Terayama, H. (1965). Exp. Cell Res. 40, 32. Weismann, B., Rowin, G., Marshall, J. \& Frederici, D. (1967). Biochemistry, 6, 207.

\section{Activity of Aminotransferases in the Tissues of Developing Lambs}

By Elizabeth M. Smith, D. A. L. Shepherd and Marjorie K. Jeacock. (Department of Physiology and Biochemistry, University of Reading, RG1 $5 A Q)$

Ballard \& Oliver (1965) have shown that liver slices from 4-month-old foetal sheep can incorporate pyruvate into glucose and that the rate of incorporation increases markedly by 1 week after birth. Since alanine and aspartate may be substrates for 
gluconeogenesis the activities of L-alanine-2-oxoglutarate aminotransferase (EC 2.6.1.2) and Laspartate-2-oxoglutarate aminotransferase (EC 2.6.1.1) were investigated in tissues of lambs before and after birth.

Two gluconeogenic tissues, liver and kidney cortex, were chosen for this investigation together with heart ventricular muscle, a tissue not normally considered to be capable of carbohydrate synthesis from amino acids. L-Aspartate-2-oxoglutarate aminotransferase activity was determined in tissue homogenates by a method (Tonhazy, White \& Umbreit, 1950) that estimates the activity of the enzyme in the cytosol only. There were significant increases in the activities of this enzyme in liver and kidney cortex from $333 \pm 152$ (mean \pm S.E.M.) and $184 \pm 153$ units in mature foetuses to $994 \pm 216$ and $865 \pm 216$ units at 1 day after birth ( 1 unit of activity is defined as 1 umole of oxaloacetate formed/hr./g. wet wt. of tissue at $37^{\circ}$ ). The activity of this enzyme in ventricular muscle showed no significant change over the same period of time, being $723 \pm 167$ units in mature foetuses and $1028 \pm 215$ units in 1-day-old lambs. There were no further significant changes in the activities of this enzyme in any of the three tissues during the first week after birth.

L-Alanine-2-oxoglutarate activity was determined in tissue homogenates by the method of Rosen, Roberts \& Nichol (1959). Activities for liver, kidney cortex and ventricular muscle in mature foetuses were $49 \pm 16,91 \pm 14$ and $50 \pm 14$ units respectively ( 1 unit of activity is defined as $1 \mu \mathrm{mole}$ of pyruvate formed/hr./g. wet wt. of tissue at $37^{\circ}$ ). By 1 day after birth enzyme activities had risen to values of $144 \pm 20,145 \pm 20$ and $135 \pm 20$ units. During the first week after birth there were no further significant changes in the activities of this enzyme in liver and kidney cortex, but a significant fall in the activity of ventricular muscle enzyme to $62 \pm 17$ units was observed.

This work was supported by a grant from the Agricultural Research Council. E.M.S. holds a Ministry of Agriculture Post-graduate Studentship.

Ballard, F. J. \& Oliver, I. T. (1965). Biochem. J. 95, 191. Rosen, F., Roberts, N. R. \& Nichol, C. A. (1959). J. biol. Chem. 234, 476.

Tonhazy, N. E., White, N. G. \& Umbreit, W. W. (1950). Arch. Biochem. 28, 36.
Factors Affecting the Changes in Activities of some Hepatic Enzymes during Development of the Rat

By Elizabeth A. Lockwood, E. Bailey and C. B. TAYLOR. (Department of Biochemistry, University of Sheffield)

Taylor, Bailey \& Bartley (1967) described the changes that occur in the activities of 'malic' enzyme, ATP citrate lyase, glucose 6-phosphate dehydrogenase and pyruvate kinase during development of the rat. Factors involved in these changes have now been investigated. Also, the developmental pattern of liver acetyl-CoA carboxylase (considered to be the rate-limiting enzyme in fatty acid biosynthesis) has been determined. Low activities of this enzyme were detected in the foetal and suckling rats. However, on weaning (21 days) activities rose to a maximum at about 40 days of age, thereafter declining to adult values. These changes in activity can be correlated with the dietary change at weaning, when a high-fat lowcarbohydrate diet is replaced by a low-fat highcarbohydrate diet.

The effects of changing the normal weaning time have been studied. Animals were weaned on to stock diet at 15 days of age and enzyme activities determined daily for 7 days. There was no change in pyruvate kinase activity, and ATP citrate lyase activity did not increase until 4 days after weaning. An increase in 'malic' enzyme activity, however, was detected less than $24 \mathrm{hr}$. after premature weaning. In other experiments rats were maintained from 14 days old until maturity (60 days) on an artificial rat milk diet. Acetyl-CoA carboxylase, ATP citrate lyase, glucose 6-phosphate dehydrogenase and pyruvate kinase activities remained constant at the low values for 14-day-old rats or decreased. 'Malic' enzyme activity increased after 22 days of age to reach normal adult values at 32 days of age. These experiments clearly indicate that 'malic' enzyme activity is controlled in part by factors other than diet.

The effect of intraperitoneal injections of various hormones (injected from 15 to 18 days of age) on hepatic enzyme activities has also been studied. Glucagon, cortisol and growth hormone were without effect on the enzymes measured. Thyroxine produced a 20-fold increase in 'malic' enzyme activity compared with control litter mates and caused a slight increase in ATP citrate lyase activity.

These results suggest that dietary changes can explain the changes in activities of most of the enzymes studied in development, but that 'malic' enzyme activity is influenced by both dietary and hormonal chạges. 